\title{
Insights on Ceramics as Dental Materials. Part I: Ceramic Material Types in Dentistry
}

\author{
Gary Willie Ho • Jukka Pekka Matinlinna
}

Received: 12 January 2011 / Accepted: 21 February 2011 /Published online: 22 March 2011

(C) The Author(s) 2011. This article is published with open access at Springerlink.com

\begin{abstract}
Ceramics are widely used biomaterials in prosthetic dentistry due to their attractive clinical properties. They are aesthetically pleasing with their color, shade and luster, and they are chemically stable. The main constituents of dental ceramic are Si-based inorganic materials, such as feldspar, quartz, and silica. Traditional feldspar-based ceramics are also referred to as "Porcelain". The crucial difference between a regular ceramic and a dental ceramic is the proportion of feldspar, quartz, and silica contained in the ceramic. A dental ceramic is a multiphase system, i.e. it contains a dispersed crystalline phase surrounded by a continuous amorphous phase (a glassy phase). Modern dental ceramics contain a higher proportion of the crystalline phase that significantly improves the biomechanical properties of ceramics. Examples of these high crystalline ceramics include lithium disilicate and zirconia.
\end{abstract}

Keywords Dental ceramics · Silicates · Silica · Porcelain . Fracture toughness $\cdot$ Ceramic materials $\cdot$ Zirconia

\section{Introduction to Si-based Inorganic Materials}

Ceramics are formally defined as compounds of metallic and non-metallic elements consisting of oxides, nitrides, carbides, and silicates. Typical silicates are formed of Sitetrahedrons, $\mathrm{SiO}_{4}{ }^{4-}$. The structure of ceramics exists in the form of crystalline solid or glasses [1]. Ceramics used in dentistry predominantly contain non-metallic and metallic

G. W. Ho $\cdot$ J. P. Matinlinna $(\bowtie)$

Dental Materials Science, Faculty of Dentistry,

The University of Hong Kong,

Hong Kong SAR, People's Republic of China

e-mail: jpmat@hku.hk elements [2] and are mostly based on silicon that is usually found in the form of silica (silicon dioxide), $\mathrm{SiO}_{2}$, due to silicon's high affinity for oxygen. A vast array of Si-O compounds and silicate minerals exists in the Earth's crust $[3,4]$. When silica occurs as a crystalline material, it can be in the form of quartz, crystobalite, and tridymite. Silica in dental ceramics is usually in the form of quartz [1]. Because of the black appearance of nitrides and carbides, they are not used as biomaterials in dentistry [2].

The traditional type of dental ceramics are feldsparbased materials containing silica fired at temperatures above $870^{\circ} \mathrm{C}$ and composed of a tectosilicate mineral feldspar $\left(\mathrm{KAlSi}_{3} \mathrm{O}_{8}\right)$, quartz $\left(\mathrm{SiO}_{2}\right)$, and kaolin $\left(\mathrm{Al}_{2} \mathrm{O}_{3}\right.$. $\left.2 \mathrm{SiO}_{2} \cdot 2 \mathrm{H}_{2} \mathrm{O}\right)[5,6]$. Because feldspar-based ceramics were prone to failure owing to their inherent brittle nature, ceramics with higher crystalline content such as alumina (aluminum trioxide), $\mathrm{Al}_{2} \mathrm{O}_{3}$, and zirconia (zirconium dioxide) $\mathrm{ZrO}_{2}$, were developed in order to improve the mechanical properties. High crystalline content ceramics are commonly used as the core (substructure) while feldspar-based ceramics are used as veneers to shield the core in prosthetic dentistry [7]. Interestingly, some calcium phosphate materials used for coating metallic subgingival dental implants are also considered ceramics, but will not be discussed in this paper [2]. Ceramics are very popular in dentistry because of their high biocompatibility and aesthetics [1].

\section{Clinical Applications}

Ceramics have three major indications in dentistry: a) ceramic-metal crowns and fixed partial dentures, b) allceramic restoration that consists of crowns, inlays, onlays, and veneers, short span anterior bridges, and c) ceramic 
denture teeth $[1,8]$. A ceramic laminate veneer is used to cover an unsightly area by bonding to the facial surface of the prepared tooth [9]. In other areas of dentistry, certain ceramics are also used for the replacement of hard tissue [10]. Any contraindications have not been reported.

\subsection{A Brief History of Dental Ceramics}

It was in 1774 that the first porcelain denture was created by Alexis Duchateau in France. However, it was not until 1838 when Elias Wildman produced dental porcelain that had reasonably good translucency and shades to match natural teeth [1]. The first porcelain jacket crowns containing either feldspar or alumina (also known as aluminous) were created in the early 1900s. Even so, the poor match in the coefficients of thermal expansion between the framework base metal alloys and the veneer ceramics led to the development of leucite-containing feldspar ceramics in the $1960 \mathrm{~s}$. By adjusting the amounts of leucite, $\mathrm{K}_{2} \mathrm{O} \cdot \mathrm{Al}_{2} \mathrm{O}_{3}$. $4 \mathrm{SiO}_{2}$, with feldspar glass, manufacturers had more control over the coefficient of thermal expansion of feldspathic porcelains and allowed the production of reliable ceramicto-metal frameworks [11].

The last few decades have been intensively focused on developing restorations without a metal substructure known as all-ceramic restorations. Today, high strength core ceramics, such as zirconia, are more and more used as a substitute for the metal substructures in prosthetic dentistry $[2,12]$.

\section{Structure of Dental Ceramics}

Dental ceramics are multiphasic as they contain a dispersed crystalline phase surrounded by a translucent glassy phase. The glassy phase has the usual properties of glass such as brittleness, non-directional fracture pattern, and translucency while the crystalline phase contributes to the overall strength of the ceramic. Some newer dental ceramics differ from traditional dental ceramics in that a larger amount of crystals have been included. The addition of crystal content improves light scatter and opacity and aids in color adaption of transparent glassy phase to dental hard tissues (enamel and dentin). More crystals in the crystalline phase make the material more stable during firing and more resistant to stresses in the mouth. The overall gain of more crystals in the crystalline phase improves mechanical strength $[1,7]$.

\subsection{Fusing Temperatures}

Dental ceramics can be categorized by firing temperatures. Temperature ranges of $1315^{\circ} \mathrm{C}$ to $1370^{\circ} \mathrm{C}$ are attributed to 'High-Fusing Ceramics', temperature ranges of $1090^{\circ} \mathrm{C}-$ $1260^{\circ} \mathrm{C}$ are called 'Medium-Fusing Ceramics,' and temperature ranges of $870^{\circ} \mathrm{C}-1065^{\circ} \mathrm{C}$ refer to 'Low-Fusing Ceramics.' High-fusing ceramics are used for denture teeth, medium-fusing ceramics for porcelain jacket restorations, and low-fusing ceramics for metal-ceramic restorations. Actually, a fourth category has been suggested described as ultra low-fusing ceramics. These ceramics are fired between $650^{\circ} \mathrm{C}$ and $850^{\circ} \mathrm{C}$. High-fusing ceramics are superior in strength, insolubility, translucency, and accuracy during repeated firings compared to medium- and low-fusing ceramics $[5,11]$.

\subsection{Type of Restoration}

Ceramics can also be classified by restoration type as shown in Fig. 1. The two major categories are named a) All-Ceramic Restorations and b) Porcelain-Fused-to-Metals/Ceramic Metal Systems [5, 12].

All-ceramic materials in dentistry are composed of a wide range of crystalline phases and may contain up to $99 \%$ by volume of crystalline phase. The amount and particle size distribution of the crystalline phase determine the aesthetical appearance and biomechanical properties. Allceramic materials can be fabricated by sintering, heatpressing, slip-casting, and machining. A disadvantage of all-ceramic restorations is more tooth structure is removed to maximize the thickness of the restoration in order to reduce the risk of fracture. This may increase pulpal pathology in some individuals [2,11-13].

The most traditional type of ceramic is feldspar-based that contains silica glasses. Feldspar-based ceramics are also known as 'Silica-Based Ceramics' and 'FeldspathicBased Ceramics'. 'Porcelain' is a term often used to describe this type of ceramic because it contains high amounts of silica [12]. To be considered a feldspar-based ceramic, it should contain a minimum $15 \mathrm{wt} \%$ of silica or silicate [14]. Feldspar-based ceramics offer extremely pleasing aesthetics because they can mimic the colors and shades of natural tooth $[12,15]$, which make them good for veneers and inlays/onlays [8,9]. Notable properties of feldspar-based ceramics are low density, resistant to chemical attacks, do not deteriorate with time, and very biocompatible $[5-7,11,12,16]$.

\section{Composition of Feldspar-Based Ceramics}

Feldspar-based ceramics are composed of $\mathrm{KAlSi}_{3} \mathrm{O}_{8}, \mathrm{SiO}_{2}$, and kaolin, $\mathrm{Al}_{2} \mathrm{O} \cdot 2 \mathrm{SiO}_{2} \cdot 2 \mathrm{H}_{2} \mathrm{O}$. Kaolin is a hydrated aluminum silicate and its role is to bind the loosely held ceramic particles together. The amount of kaolin that can be used must be limited because kaolin is opaque and natural tooth is translucent. During the process of firing porcelain, 
Fig. 1 Classification by the type of restoration

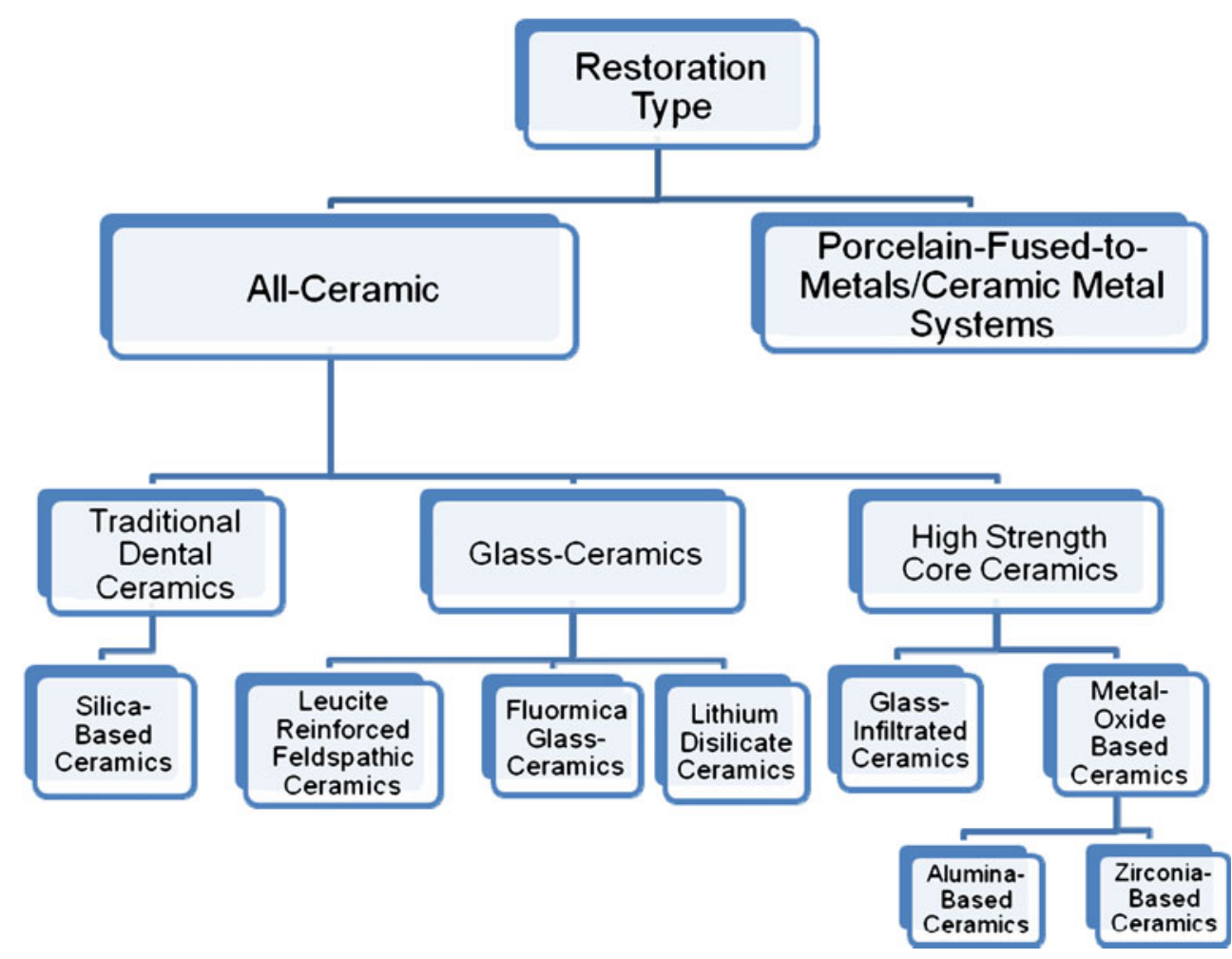

kaolin coats the non-fusible particles. Normally, less than $4 \%$ kaolin is contained in dental porcelain. After firing the ceramic, it is organized into a silica-based glassy matrix embedded in a core of crystalline substance containing silica and silicates, $\mathrm{SiO}_{4}{ }^{4-}$. Finally, they are milled to a fine powder. Silica is a reinforcing matrix component and the structure remains unchanged during the firing process. Quartz is not a strong material, so $\mathrm{Al}_{2} \mathrm{O}_{3}$ may be added as a reinforcing component. The proportion of quartz in porcelain is roughly $15 \%$ and contributes to the crystalline phase and translucency. Quartz also limits the shrinkage in porcelain $[1,5,6]$.

Feldspar is a grayish crystalline mineral found in rocks of certain geographical locations. These rocks contain Fe and mica, nevertheless, iron is an impurity that needs to be removed mechanically by splitting the feldspar rocks and examining the thin splinters visually for the presence of the impurity. The pieces of feldspar need to be ground and milled to obtain the purest powder form of feldspar. Any remaining iron impurities are removed with strong magnets [5]. Upon firing, feldspar fuses together in the glassy matrix. Potash feldspar is a mixture of potassium aluminum silicate, $\mathrm{K}_{2} \mathrm{O} \cdot \mathrm{Al}_{2} \mathrm{O}_{3} \cdot 6 \mathrm{SiO}_{2}$, which lowers the fusion temperature and viscosity and sodium aluminum silicate, $\mathrm{Na}_{2} \mathrm{O} \cdot \mathrm{Al}_{2} \mathrm{O}_{3} \cdot 6 \mathrm{SiO}_{2}$, which increases the viscosity of molten glass [6].

To further improve traditional feldspar-based ceramics, leucite, $\mathrm{K}_{2} \mathrm{O} \cdot \mathrm{Al}_{2} \mathrm{O}_{3} \cdot 4 \mathrm{SiO}_{2}$, crystals are added to the crystalline phase to enhance mechanical strength. Leucite crystals are created by further firing feldspar at $1150^{\circ} \mathrm{C}$. A crystalline phase is formed and potash becomes leucite with the release of $\mathrm{SiO}_{2}$ [6].

$\underset{\text { Potash feldspar }}{\mathrm{K}_{2} \mathrm{O} \cdot \mathrm{Al}_{2} \mathrm{O}_{3} \cdot 6 \mathrm{SiO}_{2}(\mathrm{~s})} \rightarrow \underset{\text { Leucite }}{\mathrm{K}_{2} \mathrm{O} \cdot \mathrm{Al}_{2} \mathrm{O}_{3} \cdot 4 \mathrm{SiO}_{2}(\mathrm{~s})}+\underset{\text { Silica }}{\mathrm{SiO}_{2}(\mathrm{~s})}$

Leucite provides high translucency, strength, fluorescency, and opalescency and also determines the coefficient of expansion [1].

\subsection{Properties of Silica-Based Ceramics}

The compressive strength of porcelain is in the range of 350-550 MPa. However, its tensile strength is very low, only 20-60 MPa, because of the brittle glassy nature of porcelain. Feldspar-based ceramics lack fracture toughness and are very sensitive to surface microcracks. Thus, this type of ceramic is only suitable for low stress-bearing anterior applications because of a low wear resistance $[1,5$, 6]. The shear strength of porcelain is reported to be around $110 \mathrm{MPa}$ while the diametral tensile strength is about $34 \mathrm{MPa}$. Its flexural strength is found to be around 50$75 \mathrm{MPa}$, elastic modulus approximately 69-70 GPa, and an average surface hardness is about 460 KHN (Knoop's Hardness Number) compared to $340 \mathrm{KHN}$ for enamel [5, 11]. Feldspar-based ceramics have little tolerance to plastic deformation and the coefficient of thermal expansion is about $13 \times 10^{-6} /{ }^{\circ} \mathrm{C}$, which is surprisingly closely matching enamel and dentin $[1,13]$. 


\section{Glass-Ceramics}

The so-called glass-ceramics are different from traditional feldspar-based ceramics because of the larger crystalline phase that helps stop crack growth. The presence of these crystals improves mechanical properties by reducing crack formation. The glassy phase fills the grain boundary to help create a pore-free structure. The crystalline phase grows during ceraming, i.e. conversion from a glass to a partially crystalline glass, and may occupy $50-100 \%$ of material $[1$, $5,7]$. The advantages of glass ceramics include great durability and the ability to bond to the tooth through the use of a resin luting composite $[10,13]$. The properties of glass-ceramics depend on the crystal size, the density of crystals, and the interaction between the crystals and the matrix. Glass-ceramics are easier to fabricate than traditional ceramics and do not shrink much after firing. They are also highly translucent because the glassy matrix and the crystalline phase reduce internal light scattering [5].

The first developed and identified glass ceramic was a micaceous glass composed of $45 \mathrm{vol} \%$ glass and $55 \mathrm{vol} \%$ crystalline tetrasilicic fluormica, $\mathrm{SiO}_{2} \cdot \mathrm{K}_{2} \mathrm{O} \cdot \mathrm{MgO}$. $\mathrm{Al}_{2} \mathrm{O}_{3} \cdot \mathrm{ZrO}_{2}$, and further improvements elevated fluormica crystalline content to $70 \mathrm{vol} \%$. Fluormica glass ceramics had flexure strength in the range of $120-150 \mathrm{MPa}$, which is suitable for anterior restorations but fluormica glass ceramics were eventually discontinued because of low tensile strength and poor survival rate in high stress areas in comparison to porcelain-fused-to-metal restorations [1, 17, 18].

Modern glass ceramics used today include leucitereinforced and lithium disilicate ceramics. Developed in the 1990s, leucite-reinforced ceramics contain $45 \mathrm{vol} \%$ tetragonal leucite that dramatically improves the flexural strength to $120 \mathrm{MPa}$ compared to feldspar-based ceramics. The fracture toughness of this type of ceramic is 1.61.8 $\mathrm{MPa} \mathrm{m} \mathrm{m}^{1 / 2}$, which is higher than traditional feldspar dental ceramics. It is noteworthy that this type of ceramic is used for veneers, and for anterior or posterior teeth [11, 14, 19]. Excellent aesthetics is attributed to the high translucency of leucite-reinforced ceramics [13].

Lithium disilicate, $\mathrm{Li}_{2} \mathrm{SiO}_{5}$, glasses have their flexure strength in the range of $350-450 \mathrm{MPa}$, which is even higher than that of leucite-reinforced ceramics. On the other hand, lithium disilicate glasses have a fracture toughness of 2.8-3.5 MPa m ${ }^{1 / 2}[1,20]$. These desirable biomechanical properties make them suitable for short-span fixed partial dentures, posterior crowns, and all-ceramic bridges [13]. They are less aesthetic compared to other feldspar-based glasses, thus, lithium disilicate glasses are mainly used to construct the ceramic core that provides the strength while feldspar-based ceramics are used as veneers for aesthetic reasons. Within the core, $70 \mathrm{vol} \%$ consists of the primary crystalline phase containing lithium disilicates. Lithium disilicates contain many small, randomly-oriented, interlocking, plate-like crystals that deflect cracks. A second crystalline phase is also present consisting of lithium orthophosphate, $\mathrm{Li}_{3} \mathrm{PO}_{4}$ [1]. Aesthetics of lithium disilicates can further be improved by veneering with an apatitecontaining glass-ceramic [13].

There are differences in fracture toughness between leucite-reinforced and lithium disilicate-based ceramics because leucite-reinforced ceramics have small volume of crystals compared to lithium disilicate ceramics. Increasing crystallinity of lithium disilicate ceramics provides a tighter interlocking matrix, an increased strength, and a higher fracture toughness. Lithium disilicate ceramics may tolerate significantly higher fracture loads $(705.5 \mathrm{~N})$ than leucitereinforced ceramics $(470.3 \mathrm{~N})$ when bonded to a resin composite [21].

\section{High Strength Core Ceramics}

Traditional feldspar-based ceramics used as jacket crowns were repeatedly prone to failure in stress-bearing conditions. The mechanisms of failure were related to microcrack formation in the internal surface of the crown due to the firing and the cooling process. The hostile oral environment with its temperature shocks, $\mathrm{pH}$ fluctuation, masticatory forces, parafunctions etc., promotes the stressful conditions and the inner porcelain surface is subjected to tensile stresses, allowing micro-cracks to propagate. Eventually, the cracks would reach the outer surface and it was time for a new jacket crown replacement [5].

Several ways were developed to strengthen dental ceramics: one example of them was to reinforce the core of the ceramic. The other is to combine feldspar-based ceramics with a metallic substructure [21]. Core ceramics consist of an aesthetic ceramic supported by another ceramic that provides the core and strength but lacks the desired aesthetics. Such contemporary oxide ceramics are pure alumina and zirconia in the crystalline matrix $[13,22]$. As such they are single phase microstructure without a glassy phase. Pure alumina cores contain $99.5 \%$ alumina and have their flexure strength around 487-699 MPa and fracture toughness about $4.48-6 \mathrm{MPa} \mathrm{m}^{1 / 2}[20,23,24]$. On the other hand, pure zirconia has a flexure strength of $1000 \mathrm{MPa}$ and its fracture toughness is around $10.00 \mathrm{MPa}$ $\mathrm{m}^{1 / 2}$. Feldspar-based veneers are applied to them because zirconia and alumina as substructures are opaque and dull in color. Zirconia is usually manufactured as pre-sintered blocks that may shrink up to $20 \%$ upon firing [7]. With attractive mechanical properties, however, there comes a drawback, viz. high crystalline ceramics cannot be acid etched for bonding with resin composite luting cements [13]. 


\subsection{Glass-Infiltrated Ceramics}

Glass-infiltrated ceramics contain a porous core which consists of $85 \%$ alumina infiltrated with lanthanum oxide, $\mathrm{La}_{2} \mathrm{O}_{3}$, glass. The interpenetrating phases of the two types of materials improve fracture resistance and may stop crack growth. The fracture toughness is reported to range from 2.48 to $3.55 \mathrm{MPa} \mathrm{m}^{1 / 2}$ and flexure strength is around 300 $500 \mathrm{MPa}$ [7]. Cracks cannot propagate through alumina particles as easily as glass [13]. Applications of glassinfiltrated ceramics include substructures for anterior or posterior single crown and short span anterior partial dentures [1]. Table 1 lists the commercial availability of these types of ceramics.

\subsection{Porcelain-Fused-to-Metal Restorations}

All-ceramic restorations may be described as very pleasant looking. However, they are in principle brittle and may fracture in the stressful oral environment. On the other hand, all-metal/ alloy restorations are strong, yet they lack aesthetics. By combining both materials together, a composite structure can be made consisting of the strength and toughness of metal with the aesthetics of porcelain, known as porcelain-fused-to-metals, PFM, or ceramics-metal systems $[6,12,19]$. PFM is prepared with a cast metal alloy, such as $\mathrm{Co}-\mathrm{Cr}$ and $\mathrm{Au}-\mathrm{Pd}$, and porcelain which is then fused onto the metal surface shielding the unpleasant appearance of metal or alloy. However, only an opaque shade, such as $\mathrm{TiO}_{2}$, may be applied to mask the metal appearance of metal substructure. The opaque shade makes the restoration unnatural compared to all ceramic restorations and metal alloys may elicit allergic reactions [5].

\section{Processes of Fabrication}

There are many techniques to fabricate all-ceramic restorations such as layering/sintering, heat pressing, slip casting

Table 1 Some main dental ceramics manufacturers

\begin{tabular}{lc}
\hline Type of Ceramic & Available (Manufacturer) \\
\hline Leucite-reinforced & $\begin{array}{c}\text { IPS Empress (Ivoclar Vivadent, Schaan, } \\
\text { Liechtenstein) } \\
\text { Lithium Disilicate }\end{array}$ \\
& IPS e.max (Ivoclar Vivadent, Schaan, \\
Liechtenstein) \\
Pure alumina & Procera AllCeram (Nobel Biocare, \\
& Stockholm, Sweden) \\
Pure zirconia & Lava (3M/ESPE, Neuss, Germany) \\
Glass-infiltrated & In Ceram Alumina (Vita Zahnfabrik, Bad \\
& Säckingen, Germany) \\
Leucite feldspar-based & Vitablocs Mark II (Vita Zahnfabrik, Bad \\
& Säckingen, Germany) \\
\hline
\end{tabular}

and glass-infiltration, and machining. PFM restoration fabrications require refining the surface of the metal and bringing out the desired oxide layer prior to firing the ceramic onto the metal.

\subsection{Layering and Sintering}

First, a slurry is prepared by mixing ceramic powder with modeling fluid or distilled water and the slurry is then applied in layers to a refractory die. The applied ceramic mass is blotted in order to make the piece as dense and pore free as possible before sintering. The layered piece is placed in the ceramic furnace and sintered at the required temperature, which is usually $900^{\circ} \mathrm{C}$. The sintering must be performed in vacuum so that air can escape during heating from the mass. The final product will shrink $40 \%$, therefore, the modeled piece must be larger in size. Layering is commonly used to fabricate veneers but there is always a risk of delamination because it is inevitable that some pores will be present $[1,7]$. A majority of all-ceramic restorations are sintered [12].

\subsection{Heat Pressing and Hot Pressing}

Heat pressed ceramics are fabricated using the lost wax technique performed by modeling the restoration in wax and then investing the restoration in a refractory die that forms the substructure. A highly external pressure presses the pre-sintered ingot blocks such as leucite-reinforced or lithium disilicate glass ceramics into a mold created by the burned out wax. The blocks are sintered and shaped at temperatures as high as $1180^{\circ} \mathrm{C}$ to produce all-ceramic crowns, inlays, onlays, veneers, and fixed partial dentures $[1,10,11]$.

\subsection{Slip Casting and Glass-Infiltration Fabrication}

Fine-grained $\mathrm{Al}_{2} \mathrm{O}_{3}$ powder is mixed with de-ionized water to produce a slip that is applied in layers to a gypsum die to build the substructure. Water is removed from the porous gypsum by capillary action in order for the particles to be packed closer and as dense as possible. Core materials contain approximately $85 \% \mathrm{Al}_{2} \mathrm{O}_{3}[5,25]$. The alumina core is then slowly fired up to $120^{\circ} \mathrm{C}$ to remove the water and the binding agent. The firing is gradually increased to $1120^{\circ} \mathrm{C}$ for $2 \mathrm{~h}$ with very minimal shrinkage, about $0.2 \%$. The final structure is a porous and interconnected ceramic network between the inner and the outer surface. The porous alumina substructure is glass-infiltrated with lanthanum aluminosilicate, $\mathrm{LaAl}_{2} \mathrm{O}_{3} \mathrm{SiO}_{2}$, glass. The substructure is placed on a platinum-gold alloy sheet and fired in a furnace to $1100^{\circ} \mathrm{C}$ for $4-6 \mathrm{~h}$. The glass particles melt and infiltrate into the pores by capillary diffusion $[5,7]$. The 
final product contains lesser pores, lesser flaws, and higher toughness than traditional feldspar-based ceramics. Zirconia and spinel, $\mathrm{MgAl}_{2} \mathrm{O}_{4}$, can be substituted for alumina as the core. Spinel has better aesthetics than alumina, but a compromise is a lower flexure strength, $300 \mathrm{MPa}$, while zirconia has a higher flexure strength, $700 \mathrm{MPa}$, than alumina except a tradeoff to improve strength is less translucency [1].

\subsection{Machining}

Machine systems use industrially manufactured ceramic blocks to produce high quality ceramic restorations. A replica of the restoration made of resin composite is fabricated on a master cast and a scanning tool traces the replica. The restoration is produced by a copy milling machine using a ceramic block [7].

However, these copy milling systems are slowly being replaced by CAD/CAM (Computer-Assisted DesignComputer-Assisted-Manufacture) systems. CAD/CAM systems create an optical impression of the tooth replica and the computer designs the restoration. The replica is scanned by a laser with pictures being taken while the die is rotated and the $\mathrm{CAD} / \mathrm{CAM}$ system replicates the restoration by diamond milling a replica using a densely sintered ceramic blank $[13,26]$. Scanning technology has advanced to using short wavelength blue light capable of capturing a high precision image and with a reduction in scanning time [27].

\subsection{Fabrication of PFM Restorations}

First, the metal surface must be ground or sandblasted to remove unwanted oxides and other residues to increase surface roughness, hence, improving micromechanical interlocking between the metal and ceramic. Then, the metal must be heated under vacuum to create the desired oxide coating by allowing metallic elements, such as $\mathrm{Sn}$ and $\mathrm{Zn}$ to rise upon the surface and form the oxide surface layer. Then, the third step is to remove unwanted oxide layer by acid pickling using $50 \%$ or $30 \%$ hydrofluoric acid. Lastly, a further treatment on the metal surface is carried out to create the desired thickness and quality of the oxide layer $[1,12]$.

An opaque feldspar ceramic is then fired onto the metal to hide the metal substructure. The coefficient of expansion of the metal must be greater than the coefficient of expansion of the ceramic to keep the ceramic under a state of compression caused by the metal attempting to shrink. This reduces the chance of cracking within the ceramic since the ceramic must overcome the compressive stresses [12]. Alternatively, smaller diameter sodium ions can be replaced with larger diameter potassium ions on the feldspar ceramic to put the ceramic under compression in order to minimize crack formation between the ceramic and the metal [28]. Reported improvements of 50\% increased flexure strength and 100\% improved fracture toughness are found with feldspar ceramics $[29,30]$.

\section{Summary}

We may claim that ceramics will continue to play an important role in dentistry owing to their natural aesthetics and biocompatibility. However, there will always be a compromise between aesthetics and the biomechanical strength. Good translucency requires a higher content of the glassy phase and good strength requires a higher content of the crystalline phase. Given this, there need to be a balance between the two material phases. As an idea, other types of crystals should be sought that inhibit crack growth. However, they should not contribute much by volume to the overall ceramics in order to reduce crystalline content and enhance translucency with a greater glass content. The most common clinical failures in all-ceramic and PFM restorations are delamination (chipping) and crack initiation. Bearing this in mind, careful attention must be paid to good adhesion between the restoration and the tooth tissues. The direction of dental ceramics is shifting away from using base and noble metal alloys because they may contain allergens (such as $\mathrm{Be}$ and $\mathrm{Ni}$ ) and more research needs to be devoted to all-ceramic materials because of their high, promising biocompatibility.

Open Access This article is distributed under the terms of the Creative Commons Attribution Noncommercial License which permits any noncommercial use, distribution, and reproduction in any medium, provided the original author(s) and source are credited.

\section{References}

1. van Noort R (2007) Introduction to dental materials, 3rd edn. Elsevier, Philadelphia

2. Schmalz G, Arenholt-Bindslev D (2009) Biocompatibility of dental materials. Springer, Berlin

3. Shriwer DF, Atkins PW (2001) Inorganic chemistry, 3rd edn. Oxford University Press, Oxford, pp 364-369

4. Bell CF, Lott KAK (1972) Modern approach to inorganic chemistry, 3rd edn. Butterworths, London

5. Touati B, Miara P, Nathanson D (1999) Esthetic dentistry and ceramic restorations. Martin Dunitz, London

6. Darvell BW (2006) Materials science for dentistry, 8th edn. Hong Kong

7. Hämmerle C, Sailer I, Thoma A, Hälg G, Suter A, Ramel C (2008) Dental ceramics: essential aspects for clinical practice. Quintessence, Surrey

8. Garber DA, Goldstein RE (1994) Porcelain \& composite inlays \& onlays: esthetic posterior restorations. Quintessence, Chicago

9. Gürel G (2003) The science and art of porcelain laminate veneers. Quintessence, London 
10. Holand W, Schweiger M, Frank M, Rheinberger V (2006) J Biomed Mater Res 53:297

11. Powers JM, Sakaguchi RL (2006) Craig's restorative dental materials, 12th edn. Elsevier, St. Louis

12. Powers JM, Wataha JC (2008) Dental materials: properties and manipulation, 9th edn. Elsevier, St. Louis

13. Kaminski HD, Easton AD (eds) (2009) Dental materials research. Nova Science Pub, New York, pp 1-21

14. Blatz MB, Sadan A, Kern M (2003) J Prost Dent 89:268

15. Magne P, Belser U (2002) Bonded porcelain restorations in the anterior dentition: a biomimetic approach. Quintessence, Chicago

16. Shackelford JF (1999) Advanced ceramics Volume 1 BIOCERAMICS. Overseas, Amsterdam

17. Kesley WP 3rd, Cavel T, Blankenau RJ, Barkmeier WW, Wilwerding TM, Latta MA (1995) Amer J Dent 8:259

18. Anusavice K (2003) Phillip's science of dental materials, 11th edn. Saunders, Philadelphia
19. Ubassy G (1993) Shape and color: the key to successful ceramic restorations. Quintessence, Chicago

20. Raigrodski AJ (2004) J Prost Dent 92:557

21. Clelland NL, Ramirez A, Katsube N, Seghi RR (2007) J Prost Dent 97:18

22. Heikkinen TT, Lassila LVJ, Matinlinna JP, Vallittu PK (2009) Silicon 1:199

23. Wagner WC, Chu TM (1996) J Pros Dent 76:140

24. Hefferman MJ, Aquilino SA, Diaz-Arnold AM, Haselton DR, Stanford CM, Vargas MA (2002) J Prost Dent 88:4

25. Denry IL (1996) Crit Rev Oral Bio Med 7:134

26. Mörmann WH (ed) (2006) State of the art of CAD/CAM restorations: 20 years of CEREC. Quintessence, Chicago

27. Sirona http://www.inlab.com/ecomaXL/index.php?site=inEos Main Page. Accessed on 2 Dec 2010

28. Denry IL, Holloway JA, Rosenstiel SF (1998) J Dent Res 77:583

29. Fischer H, Maier HR, Marx R (2000) Dent Mater 16:120

30. Fischer H, Marx R (2001) J Dent Res 80:336 